\title{
Two new species and updated checklist of Oxyethira Eaton, 1873 (Trichoptera, Hydroptilidae) from Brazil
}

\author{
ISABELA C. ROCHA ${ }^{1,2}$, LEANDRO L. DUMAS ${ }^{2}$ and WAGNER R.M. SOUZA ${ }^{1,2}$ \\ ${ }^{1}$ Programa de Pós-Graduação em Zoologia, Museu Nacional, Universidade Federal do Rio de \\ Janeiro, Quinta da Boa Vista, São Cristóvão, 20940-040 Rio de Janeiro, RJ, Brazil \\ ${ }^{2}$ Laboratório de Entomologia, Departamento de Zoologia, Instituto de Biologia, Universidade Federal do \\ Rio de Janeiro, Caixa Postal 68044, Cidade Universitária, 21941-971 Rio de Janeiro, RJ, Brazil
}

Manuscript received on April 3, 2017; accepted for publication on July 24, 2017

\begin{abstract}
Two new species of Oxyethira Eaton, 1873 are described: Oxyethira cascadanta sp. n. and Oxyethira quadrilobata sp. n. Description and illustrations of the new species are provided based on specimens collected in Parque Nacional da Serra da Canastra, Minas Gerais State, Southeast Brazil. Both species are assigned to the subgenus Loxotrichia but differ from other species mainly in morphology of the subgenital plate, subgenital processes and inferior appendages. Additionally, we provide an updated checklist of the Oxyethira species from Brazil.
\end{abstract}

Key words: aquatic insects, Canastra mountain range, Hydroptilinae, species list, taxonomy.

\section{INTRODUCTION}

The genus Oxyethira, erected by Eaton (1873) for two species previously occupied in Hydroptila Dalman, 1819, is the most diverse genus of Hydroptilidae (Holzenthal and Calor 2017, Morse 2017). These microcaddisflies are included in the subfamily Hydroptilinae, with other 23 genera (Holzenthal et al. 2007), and have been the subject of several works describing new species, especially in the Neotropical Region (Angrisano and Sganga 2009, Santos et al. 2009, Thomson and Holzenthal 2012, Souza and Santos 2017). However, the diversity of Oxyethira is poorly known and several

Correspondence to: Isabela Cristina Rocha

E-mail: isaabio@hotmail.com undescribed species are still to be found, not only in unexplored regions but also in localities previously studied (Souza and Santos 2017).

Over 200 species of Oxyethira are known from all biogeographical regions (Morse 2017, Souza and Santos 2017). Adults of Neotropical Oxyethira are recognized by having head and antennae unmodified, three ocelli, maxillary palps with five segments, labial palps with three segments, tibial spur formula 0-3-4, venation distinct with veins reaching wing margin, mesoscutellum without transverse suture, metascutellum pentagonal and abdomen without visible modifications (Marshall 1979, Kelley 1984, Souza and Santos 2017).

In Brazil, 34 species are reported in five subgenera: Dactylotrichia Kelley, 1984, 
Dampfitrichia Mosely, 1937, Loxotrichia Mosely, 1939, Oxytrichia Mosely, 1939 and Tanytrichia Kelley, 1984 (Santos et al. 2017, Souza and Santos 2017). Others subgenera are recognized, but because of the large morphological differences observed in the groups, many species remain unplaced to any of them.

Currently, four species of Oxyethira are registered from Minas Gerais State: Oxyethira espinada Holzenthal \& Harris, 1992, O. parce (Edwards \& Arnold, 1961), O. tica Holzenthal \& Harris, 1992 and O. zilaba (Mosely, 1939). Here we provide descriptions and illustrations of two new species based on specimens collected in Parque Nacional da Serra da Canastra, a protected area in the Cerrado biome, Minas Gerais State, Southeast Brazil. Additionally, we provide an updated checklist of the Oxyethira species from Brazil (Table I).

The ZooBank Life Science Identifier (LSID) of this publication is: urn:lsid:zoobank. org:pub:AF 8 8D 809 - FA 46-407 A - 817 F B9CD1D93A352

\section{MATERIALS AND METHODS}

The adult specimens were collected with Pennsylvania light traps (Frost 1957) and preserved in $96 \%$ ethanol. In order to observe genital structures, male abdomens were diaphanized in a heated $\mathrm{KOH}$ $10 \%$ solution, then kept in $50 \%$ acetic acid for five minutes, washed in distilled water and transferred to $96 \%$ ethanol. Genitalia were examined under a compound microscope (Carl Zeiss, Axio Lab) equipped with a camera lucida, and their diagnostic structures drawn in pencil. The sketches were used as templates to trace graphic vectors in ADOBE ILLUSTRATOR (v. 16.0.0, Adobe Systems, Inc.). The terminology for morphology follows Kelley (1984).

The specimens examined are deposited in the Coleção Entomológica Professor José Alfredo
Pinheiro Dutra, Departamento de Zoologia, Universidade Federal do Rio de Janeiro, Rio de Janeiro, Brazil (DZRJ).

\section{RESULTS}

\section{Oxyethira cascadanta sp. n.}

Figures 1-4

ZooBank Life Science Identifier (LSID) urn:1sid:zoobank.org:act:3721A5B4-6364-489E8679-C079AAFDB132

Description. Adult male. Forewing length: male holotype, $2.3 \mathrm{~mm}$; male paratype, $2.5 \mathrm{~mm}$. Head yellowish-brown with brown setae. Dorsum of thorax light-brown, yellowish-brown laterally. Fore- and hind wings covered with light brown setae. Segment VII annulate with small patch of setae anterior to the mesoventral process. Tergum VIII setose, posterodorsal margin U-shaped, sternum with deep mesal incision reaching anterior margin of the segment.

Genitalia. Sternum IX with anterolateral margin elongate, rounded anteriorly, retracted within segments VI-VIII, posterolateral margin with acute dorsal lobe, projected dorsad. Segment $\mathrm{X}$ membranous, difficult to discern. Inferior appendages fused to sternum IX, elongate, tapering posteriorly with bifid apex, interior mesal surface with two setose and slender membranous processes mesally connected. Subgenital plate long; in dorsal view (Fig. 1), anterior half narrow, posterior half enlarged, subtriangular, slightly crenulate and rounded at apex; in lateral view (Fig. 3), dorsal margin undulate, slightly concave ventrally with apex acute, beak-like, pointed downward. Subgenital processes slender; in dorsal view (Fig. 2), paired, asymmetrical (right process longer than left), both excavated apicodorsally with single short setae subapically; in lateral view (Fig. 3), strongly curved basally, apex directed apicodorsad, curved at tip. Phallus tubular, elongate, rod-like, stouter at 


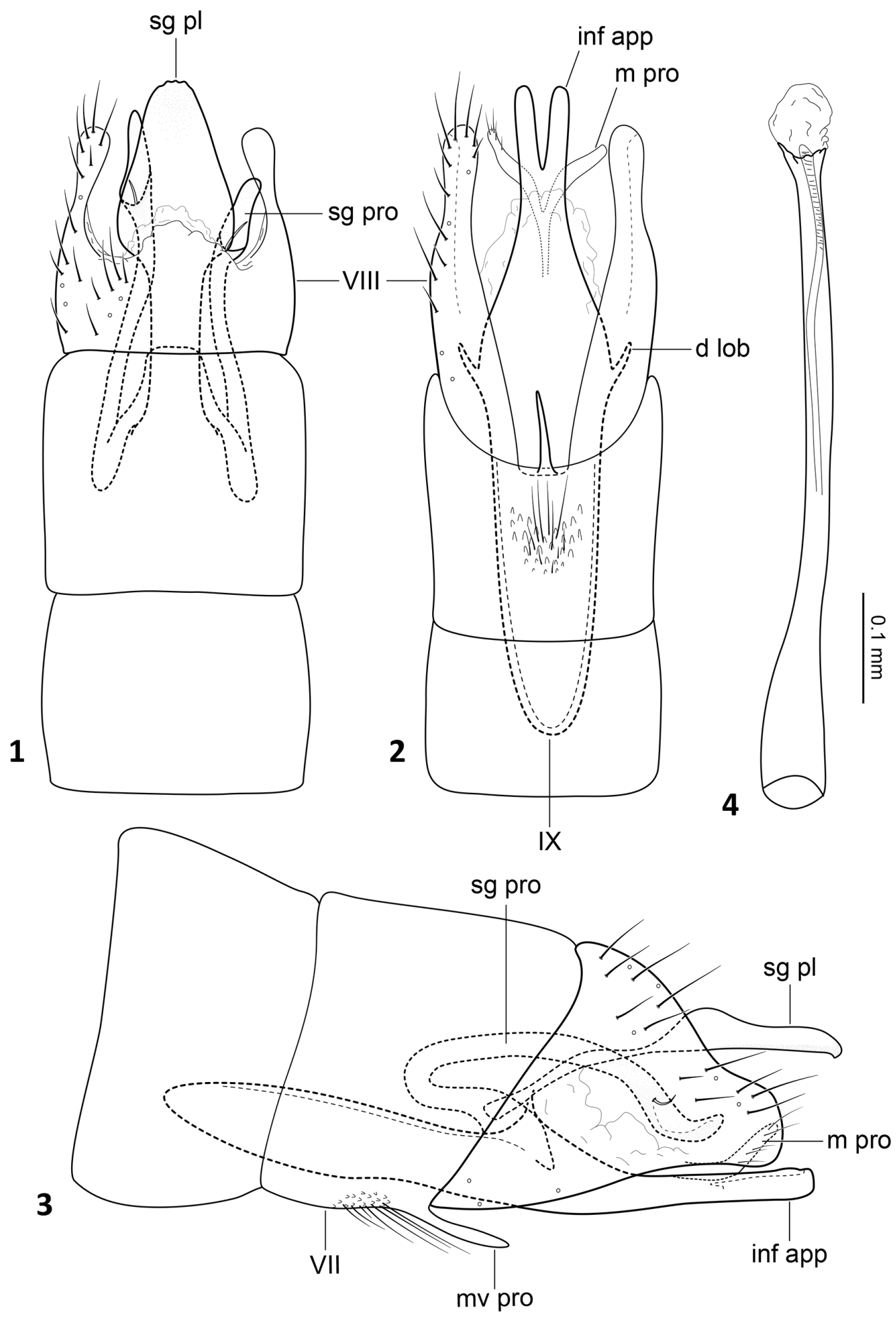

Figures 1-4 - Oxyethira cascadanta sp. n. Male genitalia (holotype). 1. Dorsal view; 2. Ventral view; 3. Lateral view, left; 4. Phallus, dorsal view. Abbreviations: d lob - dorsal lobe; inf app - inferior appendage; m pro membranous processes; mv pro - mesoventral process; sg pl - subgenital plate; sg pro - subgenital processes; VII - sternum VII; VIII - segment VIII; IX - sternum IX. 
base than apex, apex membranous, ejaculatory duct slightly sclerotized and protruding (Fig. 4).

Female and immatures. Unknown.

Taxonomic notes. Based on the deep mesal incision of the sternum VIII and the pair of asymmetric subgenital processes, the new species is assigned to the subgenus Loxotrichia. Oxyethira cascadanta $\mathrm{sp}$. $\mathrm{n}$. is most similar to O. azteca (Mosely, 1937), having the inferior appendages fused basally, bifid distally, forming a long, slender fork. These species also share with O. quadrilobata sp. n. asymmetrical and strongly curved subgenital processes, each with a single subapical short seta. Additionally, O. cascadanta sp. n. has two setose and slender membranous processes on the interior mesal surface of the inferior appendages, also present in O. copina Angrisano, 1995, O. dalmeria (Mosely, 1937) and O. quadrilobata sp. n., but absent in $O$. azteca. The subtriangular posterior half of the subgenital plate distinguishes $O$. cascadanta sp. n. from all congeners.

Type material. Holotype male: Brazil, Minas Gerais, São Roque de Minas, Parque Nacional da Serra da Canastra, parte baixa da Cachoeira Casca D'anta, Rio São Francisco, 20¹8.54'S, $46^{\circ} 31.37^{\prime} \mathrm{W}$, ca $900 \mathrm{~m}$ elev, 03.IV.2014, JL Nessimian, LL Dumas, ALH Oliveira \& SP Gomes leg. (DZRJ). Paratype: 1 male, same data as holotype (DZRJ).

Distribution. Brazil: Minas Gerais.

Etymology. The specific epithet of the new species refers to the Cachoeira Casca D'anta, the largest waterfall of the São Francisco River, where the specimens were collected.

\section{Oxyethira quadrilobata sp. n.}

Figures 5-8

ZooBank Life Science Identifier (LSID) urn:1sid:zoobank.org:act:469A759C-E472-48248A86-BE88A9817CE4
Description. Adult male. Forewing length: male holotype, $2.2 \mathrm{~mm}$; male paratypes, 2.1-2.5 $\mathrm{mm}(\mathrm{n}=8)$. Head yellowish-brown with brown setae. Dorsum of thorax brown, yellowish-brown laterally. Fore- and hind wings covered with light brown setae. Sternum VII with small patch of setae anterior to mesoventral process. Tergum VIII setose, in dorsal view (Fig. 5) subrectangular; in lateral view (Fig. 7) subtrapezoidal; sternum with deep mesal U-shaped incision, almost reaching anterior margin of segment.

Genitalia. Sternum IX with anterolateral margin elongate, pointed anteriorly, retracted within segments VI-VIII, posterolateral margin with curved and acute dorsal lobe, produced anterodorsad. Segment X membranous, difficult to discern. Inferior appendages fused to sternum IX, elongate, divided apically into four rounded lobes, interior mesal surface with two setose and slender membranous processes, connected mesally. Subgenital plate long and slender; in dorsal view (Fig. 5) slightly expanded subapically, digitiform projection at anterodorsal margin with circular opening at base; in lateral view (Fig. 7), scimitarlike, slightly curved, with anterodorsal digitiform projection directed posterad. Subgenital processes slender, asymmetrically paired (left process slightly longer than the right), subapically with a single short dorsal setae; in lateral view (Fig. 7), strongly curved at base, apically acute. Phallus tubular, elongate, narrow, stouter at base than apex, apex membranous with ejaculatory duct slightly sclerotized, not protruding (Fig. 8).

Female and immatures. Unknown.

Taxonomic notes. As in other species of the subgenus Loxotrichia, the new species also has a deep mesal incision in the sternum VIII, as well as having two asymmetrical subgenital processes. Oxyethira quadrilobata sp. n. is very similar to $O$. cascadanta sp. n. as discussed under that species. 


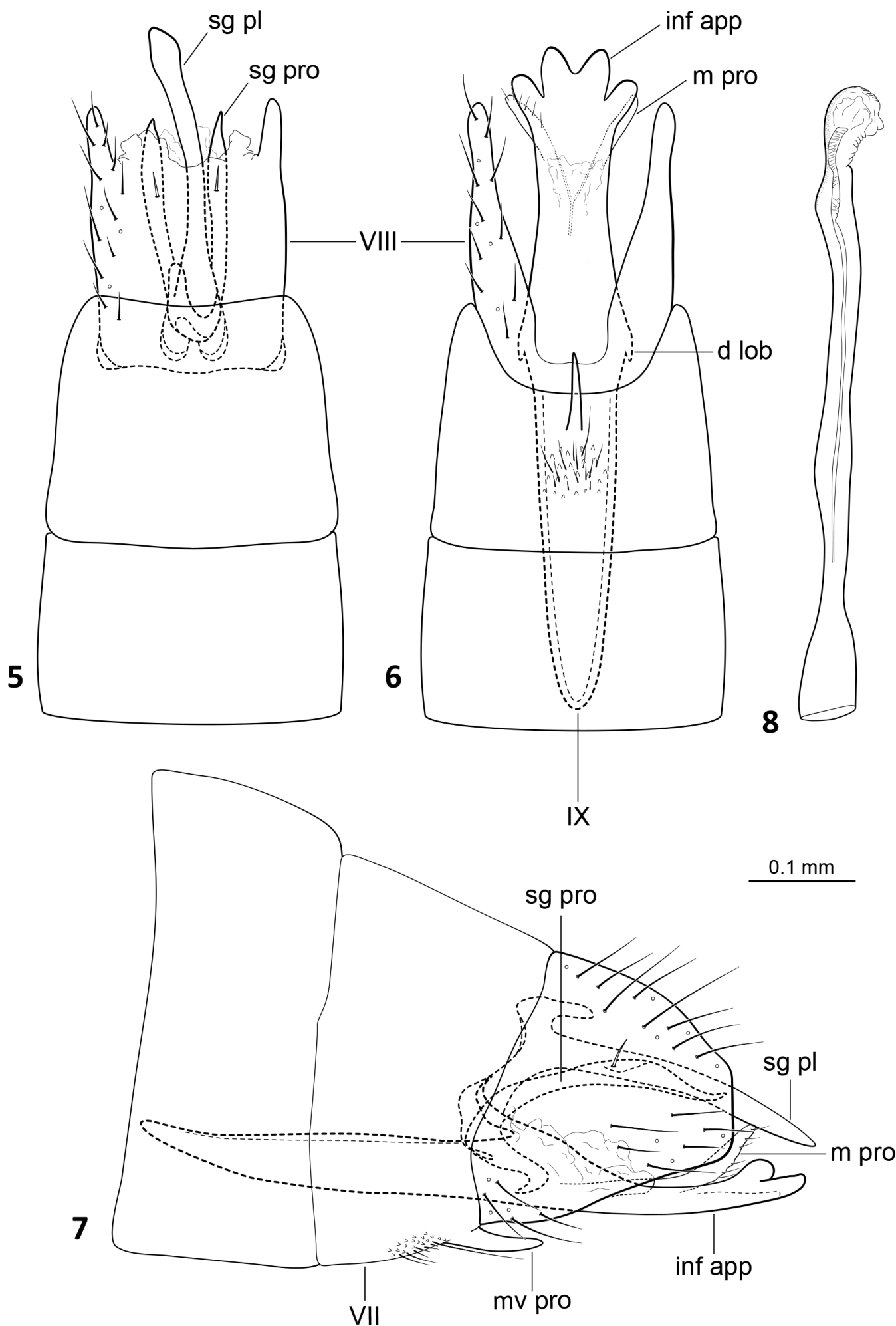

Figures 5-8 - Oxyethira quadrilobata sp. n. Male genitalia (holotype). 5. Dorsal view; 6. Ventral view; 7. Lateral view, left; 8. Phallus, dorsal view. Abbreviations: d lob - dorsal lobe; inf app - inferior appendage; m pro - membranous processes; mv pro - mesoventral process; sg pl - subgenital plate; sg pro - subgenital processes; VII - sternum VII; VIII - segment VIII; IX - sternum IX. 
However, it can be easily distinguished from all congeners by the distinct inferior appendages, fused basally and divided apically into four lobes, and the elongate and slender subgenital plate directed anterodorsally.

Type material. Holotype male: Brazil, Minas Gerais, São Roque de Minas, Parque Nacional da Serra da Canastra, parte baixa da Cachoeira Casca D’anta, Rio São Francisco, 20¹8.54’S, $46^{\circ} 31.37^{\prime} \mathrm{W}$, ca $900 \mathrm{~m}$ elev., 03.IV.2014, JL Nessimian, LL Dumas, ALH Oliveira \& SP Gomes leg. (DZRJ). Paratypes: 8 males, same data as holotype (DZRJ).

Distribution. Brazil: Minas Gerais.

Etymology. The name quadrilobata (Latin: quadri = four; greek: lobulo = prominent part of an organ) refers to the distinctive shape of the fused inferior appendages, divided apically into four rounded lobes.

\section{ACKNOWLEDGMENTS}

We are grateful to the Laboratório de Entomologia (UFRJ) team, especially for the assistance of Dr. Jorge Luis Nessimian during the collection expeditions and for valuable comments on the identity and description of these new species. The authors thank the Conselho Nacional de Desenvolvimento Científico e Tecnológico (CNPq), Coordenação de Aperfeiçoamento de Pessoal de Nível Superior (CAPES) and Fundação de Amparo à Pesquisa do Estado do Rio de Janeiro (FAPERJ) for the fellowships. The Instituto Brasileiro do Meio Ambiente e dos Recursos Naturais

TABLE I

List of Oxyethira species known from Brazil. State abbreviations: AL - Alagoas; AM - Amazonas; BA - Bahia; CE Ceará; MA - Maranhão; MG - Minas Gerais; PA - Pará; PB - Paraíba; PE - Pernambuco; PI - Piauí; PR - Paraná; RJ - Rio de Janeiro; RR - Roraima; SC - Santa Catarina; SE - Sergipe; SP - São Paulo.

Subgenus / Species

Oxyethira (Dactylotrichia) Kelley, 1984

Oxyethira guariba Souza \& Santos, 2017

Oxyethira iannuzzae Souza \& Santos, 2017

Oxyethira retrosa Souza \& Santos, 2017

Oxyethira santiagensis Flint, 1982

Oxyethira (Dampfitrichia) Mosely, 1937

Oxyethira calori Souza \& Santos, 2017

Oxyethira circarverna Kelley, 1983

Oxyethira discaelata Kelley, 1983

Oxyethira hyalina (Müller, 1879)

Oxyethira lagunita Flint, 1982

Oxyethira spissa Kelley, 1983

Oxyethira (Loxotrichia) Mosely, 1939

Oxyethira cascadanta $\mathrm{sp} . \mathrm{n}$.

Oxyethira gracilianoi Souza \& Santos, 2017

Oxyethira parce (Edwards \& Arnold, 1961)

Oxyethira quadrilobata sp. n.
Distribution / Reference

PB (Souza and Santos 2017)

AL, BA (Souza and Santos 2017)

AL, SE (Souza and Santos 2017)

Brazil (Kelley 1984, Paprocki et al. 2004)

BA (Souza and Santos 2017)

AM (Santos et. al 2009), BA, MA, PB (Souza and Santos 2017)

AM (Kelley 1983, Paprocki et al. 2004)

SC (Müller 1879, Paprocki et al. 2004)

PR (Kelley 1984, Paprocki et al. 2004)

AM, PA (Kelley 1984, Paprocki et al. 2004)

MG

AL, BA (Souza and Santos 2017)

CE (Takiya et al. 2016), MG (Blahnik et al. 2004, Paprocki et al. 2004)

MG 
TABLE I (continuation)

\begin{tabular}{|c|c|}
\hline Subgenus / Species & Distribution / Reference \\
\hline Oxyethira tica Holzenthal \& Harris, 1992 & $\begin{array}{l}\text { AM (Santos et al. 2009), AL, BA, MA, PB, PE, SE (Souza } \\
\text { and Santos 2017), CE, PI, RJ (Takiya et al. 2016), MG } \\
\text { (Blahnik et al. 2004) }\end{array}$ \\
\hline Oxyethira zilaba (Mosely, 1939) & MG, PR, SC, SP (Mosely 1939, Paprocki et al. 2004) \\
\hline \multicolumn{2}{|l|}{ Oxyethira (Oxytrichia) Mosely, 1939} \\
\hline $\begin{array}{l}\text { Oxyethira longipenis Santos, Henriques-Oliveira \& Nessimian, } \\
2009\end{array}$ & AM (Santos et al. 2009) \\
\hline Oxyethira peruviana Harris \& Davenport, 1999 & AM (Santos et al. 2009) \\
\hline Oxyethira presilla Harris \& Davenport, 1999 & AM (Santos et al. 2009) \\
\hline Oxyethira sinistra Santos, Henriques-Oliveira \& Nessimian, 2009 & AM (Santos et al. 2009) \\
\hline Oxyethira spirogyrae (Müller, 1879) & SC (Müller 1879, Paprocki et al. 2004) \\
\hline \multicolumn{2}{|l|}{ Oxyethira (Tanytrichia) Kelley, 1984} \\
\hline Oxyethira bettyae Thomson \& Holzenthal, 2012 & PE (Souza et al. 2013) \\
\hline Oxyethira bicornuta Kelley, 1983 & AM (Kelley 1983, Paprocki et al. 2004) \\
\hline Oxyethira espinada Holzenthal \& Harris, 1992 & $\begin{array}{l}\text { AL (Souza and Santos 2017), MG (Blahnik et al. 2004, } \\
\text { Paprocki et al. 2004) }\end{array}$ \\
\hline Oxyethira longissima Flint, 1974 & AM (Santos et al. 2009) \\
\hline Oxyethira luanae Santos, Henriques-Oliveria \& Nessimian, 2009 & AM (Santos et al. 2009) \\
\hline Oxyethira macrosterna Flint, 1974 & AM (Santos et al. 2009), MA (Souza and Santos 2017) \\
\hline Oxyethira merga Kelley, 1983 & $\begin{array}{l}\text { BA (Souza and Santos 2017), PI (Takiya et al. 2016), RR } \\
\text { (Flint 1991, Paprocki et al. 2004) }\end{array}$ \\
\hline Oxyethira picita Harris \& Davenport, 1999 & AM (Santos et al. 2009) \\
\hline Oxyethira septentrionalis Souza \& Santos, 2017 & PI (Souza and Santos 2017) \\
\hline Oxyethira singularis Souza \& Santos, 2017 & BA (Souza and Santos 2017) \\
\hline Oxyethira una Souza \& Santos, 2017 & BA (Souza and Santos 2017) \\
\hline \multicolumn{2}{|l|}{ Incertae sedis } \\
\hline Oxyethira brasiliensis Kelley, 1983 & PA (Kelley 1983, Paprocki et al. 2004) \\
\hline Oxyethira diplospissa Souza \& Santos, 2017 & AL (Souza and Santos 2017) \\
\hline Oxyethira maranhensis Souza \& Santos, 2017 & MA (Souza and Santos 2017) \\
\hline Oxyethira rafaeli Souza \& Santos, 2017 & BA, PI (Souza and Santos 2017) \\
\hline
\end{tabular}

Renováveis (IBAMA), the Instituto Chico Mendes de Conservação da Biodiversidade (ICMBio) and the Parque Nacional da Serra da Canastra staff are thanked for issuing collecting permits and allowing us to use their field facilities.

\section{REFERENCES}

ANGRISANO EB AND SGANGA JL. 2009. New species of Hydroptilidae (Trichoptera) from Salto Encantado
Provincial Park (Misiones province, Argentina). Zootaxa 2162: 57-68.

BLAHNIK RJ, PAPROCKI H AND HOLZENTHAL RW. 2004. New distribution and species records of Trichoptera from southern and southeastern Brazil. Biota Neotrop 4: 1-6.

DALMAN JW. 1819. Nogra nya insecta-genera beskrifna. Vet Akad Hand 40: 117-127.

EATON KJ. 1873. On the Hydroptilidae, a family of Trichoptera. T Roy Ent Soc London 1873: 125-150.

EDWARDS SW AND ARNOLD CR. 1961. The caddis flies of the San Marcos river. Tex J Sci 13: 398-415.

FLINT OS. 1974. The Trichoptera of Surinam. Studies of Neotropical caddisflies, XV. Stud Fau Surin Guyan 14: 1-151 
FLINT OS. 1982. Studies of Neotropical caddisflies, XXXI: five new species from Argentina (Trichoptera). Entomol News 93: 43-47.

FLINT OS. 1991. Studies of Neotropical caddisflies, XLIV: on a collection from Ilha de Maraca, Brazil. Acta Amaz 21: 63-83.

FROST SW. 1957. The Pennsylvania insect light trap. J Econ Entomol 50: 287-292.

HARRIS SC AND DAVENPORT LJ. 1999. New species of Hydroptilidae (Trichoptera) from the Amazon region of northeastern Peru. Proc Entomol Soc Wash 101: 26-38.

HOLZENTHAL RW, BLAHNIK RJ, PRATHER AL AND KJER KM. 2007. Order Trichoptera Kirby, 1813 (Insecta), caddisflies. Zootaxa 1668: 639-698.

HOLZENTHAL RW AND CALOR AR. 2017. Catalog of the Neotropical Trichoptera (Caddisflies). ZooKeys 654: 1-566.

HOLZENTHAL RW AND HARRIS SC. 1992. Hydroptilidae (Trichoptera) of Costa Rica: the genus Oxyethira Eaton. J N Y Entomol Soc 100: 155-177.

KELLEY RW. 1983. New Neotropical species of Oxyethira (Trichoptera: Hydroptilidae). P Entomol Soc Wash 85: 41-54.

KELLEY RW. 1984. Phylogeny, morphology and classification of the micro-caddisfly genus Oxyethira Eaton (Trichoptera: Hydroptilidae). T Am Entomol Soc 110: 435-463.

MARSHALL JE. 1979. A review of the genera of the Hydroptilidae (Trichoptera). Bull Br Mus (Nat Hist) Entomol Ser 39(3): 135-239.

MORSE JC. 2017. Trichoptera World Checklist. http://entweb. clemson.edu/database/trichopt/index.htm.

MOSELY ME. 1937. Mexican Hydroptilidae (Trichoptera). T Roy Ent Soc London 86: 151-189.
MOSELY ME. 1939. The Brazilian Hydroptilidae (Trichoptera). Novit Zool 41: 217-239.

MÜLLER F. 1879. Notes on the cases of some South Brazilian Trichoptera. T Roy Ent Soc London 4: 131-144.

PAPROCKI H, HOLZENTHAL RW AND BLAHNIK RJ. 2004. Checklist of the Trichoptera (Insecta) of Brazil I. Biota Neotrop 4: 1-22.

SANTOS APM, CALOR AR, DUMAS LL, PES AMO, SOUZA WRM, HENRIQUES-OLIVEIRA AL AND CAMARGOS LM. 2017. Trichoptera in: Catálogo Taxonômico da Fauna do Brasil. http://fauna.jbrj.gov.br/ fauna/faunadobrasil/278.

SANTOS APM, HENRIQUES-OLIVEIRA AL AND NESSIMIAN JL. 2009. New species and records of Oxyethira Eaton (Trichoptera: Hydroptilidae) from Amazonas State, Brazil. Zootaxa 2169: 35-44.

SOUZA WRM AND SANTOS APM. 2017. Taxonomic study of the genus Oxyethira Eaton 1873 (Trichoptera: Hydroptilidae) from Northeastern Brazil: eleven new species and distributional records. Zootaxa 4236(3): 484506.

SOUZA WRM, SANTOS APM, LIMA LRC AND PINHEIRO US. 2013. A new species and new records of microcaddisflies (Trichoptera: Hydroptilidae) from northeastern Brazil. Zootaxa 3700(4): 583-587.

TAKIYA DM ET AL. 2016. Aquatic Insects from the Caatinga: checklists and diversity assessments of Ubajara (Ceará State) and Sete Cidades (Piauí State) National Parks, Northeastern Brazil. Biodivers Data J 4: e8354.

THOMSON RE AND HOLZENTHAL RW. 2012. New species and records of Hydroptilidae (Trichoptera) from Venezuela. ZooKeys 185: 19-39. 